ModaPalavra E-periódico

\title{
Além das aparências
}

\section{Selediana de Souza Godinho}




\section{Além das Aparências Selediana de Souza Godinho}

\section{Resumo}

O objetivo deste artigo é descrever a importância da aparência no campo da deficiência, além de enfatizar o quanto o vestuário aparece como expressão corporal, que não somente se relaciona à proteção do indivíduo, mas também como um desafio na realidade social das pessoas com deficiência. A revisão de uma literatura estilística depreende-se que no mundo estereotipado a imagem corporal é um elemento notável e se relaciona diretamente com um desejo de se vangloriar, neste caso a roupa atua, para as pessoas com deficiência como uma estratégia de se aceitar, diferenciar e se incluir socialmente.

Palavras- chave: Aparência; Deficiência; Roupa.

\begin{abstract}
The purpose of this article is to describe the importance of appearance in the field of disability, and emphasize how the clothing appears as body language, which not only relates to protection of the individual, but also as a challenge in the social reality of people with disabilities. The review of a stylistic literature it appears that the world stereotypical body image is a striking element and is directly related to a desire to boast, in this case the clothing acts, for people with special needs, as a strategy to accept differentiate and include socially.
\end{abstract}

Keywords: Appearance; Disable;

Clothes. 


\section{INTRODUÇÃO}

Observa-se a deficiência como narrativa cultural de um corpo - ser, considerado "diferente" e que transita entre o doente, deformado, velho, anormal ou debilitado. Neste cenário é clara a percepção de que o indivíduo com deficiência afastase dos padrões construídos por uma sociedade, a qual o que se valoriza e preserva é uma estética de um corpo narcisista, escultural e saudável, neste caso, o que se descreve em uma localidade contemporânea é uma universalização de um físico que se encaixa a um padrão (medida) habitual e/ou neutro.

No entanto, é dentro deste campo que se coloca um grave problema epistemológico do qual a aparência não pode estar universalizada e definida somente por uma particularidade de um corpo colocado em desacordo com o ambiente social. Considera-se que estabelecer a deficiência apenas como um estado físico implica em pensar coercitivamente em uma única existência de corporeidade, a qual somente aceita o que é perfeito e bonito.

É assim que geralmente a deficiência é empregada no campo da estética e da moda, em que a beleza é imposta por um sistema de valores que se enquadram em um estereótipo universal ou subjetivo, além do que, não podemos nos esquecer da construção sociocultural de uma beleza, principalmente eurocêntrica, a qual o belo está diretamente relacionado a um estado corpóreo que não aceita outro tipo de físico que não seja o magro, esbelto e sem anormalidades.

Por outro lado, está também, o conceito de imagem corporal - como a forma de perceber a aparência física e o desejo do ser em se enquadrar num contexto social, econômico e cultural. Neste sentido, observa-se em primeira instância uma imagem que se relaciona à percepção que cada indivíduo tem frente às necessidades, desejos, crenças e ações, isto é, a forma como queremos nos apresentar diante de um determinado grupo e, neste caso, a inclusão social de um corpo deficiente, a necessidade de pertencer a um grupo, vai além do estereótipo, ou seja, além daquilo que os olhos possam transparecer daquele físico "anormal".

Por conseguinte, coloca-se a moda, especificamente a vestimenta, como um produto social que possibilita enxergar a deficiência além de um olhar clínico e se assenta nas necessidades e desejos de pessoas com deficiência, como parte dinâmica que ultrapassa a efemeridade de um imaginário sociocultural. 
Sem dúvida que as roupas, com seus códigos de vestuário, são regras estipuladas e ditam a aparência física. A estilística tem um significado sociocultural, que segue sempre a certas expectativas e se regem de acordo a circunstâncias e ocasiões, desta maneira, questiona-se neste artigo sobre: Que acontece quando a moda ultrapassa os limites da beleza e do jogo das aparências se consolida na deficiência?

O objetivo aqui é de abordar a importância da aparência no campo da deficiência, em um enfoque no qual o vestuário aparece como expressão corporal que não só se relaciona à proteção do indivíduo, mas também como um desafio na realidade social das pessoas com deficiência, sendo assim, primeiro se apresenta os principais suportes teóricos sobre imagem social e o mundo das aparências, segundo se expõe sobre a relevância da roupa no contexto sociocultural das pessoas com deficiência.

A pretensão é obter uma visão interdisciplinar mediante a apresentação social da moda no campo de estudos sobre deficiência.

\section{DA IMAGEM CORPORAL AO CAMPO DAS APARÊNCIAS}

Nota-se que, na estrutura sociológica é comum em determinados grupos, a valorização de características que se apresentam como dominantes em diferentes cenários. De acordo com Goffman (2007) é uma interpretação do mundo onde vivem vários "eus" de cada indivíduo, os quais apresentam e representam como em um teatro, em que ações cotidianas são formadas e permitem que os indivíduos observem a vestimenta do outro, seus gestos, tom de voz e olhar, entre outros aspectos aparentes, assim a construção de uma imagem está diretamente relacionada com o corpo.

Esta questão surgiu em 1920 nos estudos de psicologia de Paul Schilder, que coloca a imagem como um reflexo das atitudes e interações do indivíduo com outros, segundo o teórico, a imagem que a pessoa forma em sua mente (Schilder, 1999).

Este teórico descreve que a percepção de si e do corpo faz com que o indivíduo revele suas emoções e personalidade, suas ações e desejos, também ao mesmo tempo é essa projeção da imagem corporal, que gera identificação e atitudes diferentes em relação aos demais. A imagem corporal é o próprio físico em uma construção mental e como o mesmo é percebido individual e socialmente, isso significa que há uma imagem do corpo que pode ser aceita ou não, por uma sociedade. Observa-se que a 
imagem corporal é influenciada diretamente pelo sociocultural, ou seja, o corpo se ajusta às exigências e regulamentos do meio em que o ser está inserido (Schilder, 1999).

Considera Schilder (1999), que a experiência pragmática do indivíduo na existência de uma unidade do corpo, vai além de uma simples percepção e se traduz em um esquema corporal, que enfatiza a importância do conhecimento de como este se posiciona, ou seja, que modelo postural existe, logo, a imagem física é um olhar tridimensional que um ser tem de si mesmo, isso significa que existe uma aparência do corpo que perpassa uma mera representação e atua em distintos níveis da percepção humana.

Segundo Secchi, Camargo e Bertoldo (2009), a estrutura sociológica segue a tendências, onde determinados grupos étnicos, seguindo a "onda do modismo", costumam valorizar o indivíduo conforme a roupa, os acessórios, seus gestos. Os autores também seguem a análise de Schilder, para justificar o ponto de vista de ambos, visto que é a partir da experiência pessoal, juntamente com a dos “outros" em relação ao corpo, que o indivíduo se posiciona no lócus que vive.

A visão, fundamentada pelos autores, serve de referência para colocar a imagem corporal também no campo da Sociologia, na qual o contexto atua sobre a imagem física através dos variados comportamentos que está implicitamente relacionada às experiências humanas, como por exemplo, as influências culturais as quais fazem com que o indivíduo matiza sua autopercepção do corpo (Schilder, 1999, Cash, 2004, Secchi, Camargo e Bertoldo, 2009).

Seguindo este marco de análises, Goffman (2007, p.48) explica que o indivíduo age de acordo com os desejos que pretende transmitir a partir de um referencial o qual recebe e que está, ao mesmo tempo, relacionado às ações que implicam a um cotidiano, em um constante processo de identificação e diferenciação de indivíduos e grupos. "O desempenho de papéis sociais relacionado com a forma como cada indivíduo vê sua imagem e visa manter".

Para Barreiro (2004) a imagem corporal se constitui em um instrumento de expressão, no qual o indivíduo atua em relação ao mundo externado em uma constante comparação com outros corpos e objetos. Considera-se que essa manifestação entre o corpo autopercebido e a visão dos demais é que coloca as relações humanas como parte de um processo de socialização. 
E o que acontece quando a imagem corporal se constrói a partir de alguma deficiência? Como o indivíduo se percebe e é percebido no meio de um convívio social? Tais questionamentos remetem a um esquema de corporeidade que não se enquadra nas normas da sociedade moderna, principalmente pelas diferenças que existem em um corpo com deficiência. Deste modo pessoas com deficiência são excluídas da vida social, pois não correspondem ao estereótipo do corpo ideal e narcisista.

Conforme Tavares (2003) a imagem corporal se constrói na representação mental da identidade do corpo, que é influenciado pelo fisiológico, sociológico e por aspectos emocionais. Em relação à deficiência, a imagem física se relaciona diretamente com a aparência que por sua vez parece definir as restrições para uma ação social.

Conforme a Classificação Internacional de Funcionalidades - CIF (2001), a Deficiência pode ser entendida como o resultado das limitações na atividade e nas restrições, derivadas de uma deficiência no campo da saúde, que afetam um indivíduo em seu desenvolvimento e em sua vida cotidiana, dentro do ambiente físico e social.

Esse conceito permite observar que relacionar a deficiência à percepção corporal ou colocá-la diretamente no mundo das aparências, significa reconhecer que esta não pode ser resultado de um problema de saúde pessoal, mas sim um produto da interação entre um corpo com deficiência e tudo aquilo que o meio social oferece, para que ocorra uma participação. Para Pantano (2007) a deficiência está relacionada diretamente ao meio em qual o ser se socializa e se desenvolve.

Para Rodríguez (2009) a imagem corporal tem uma estreita associação com a deficiência, uma vez que a pessoa compara seu corpo a um funcionamento que este deve ter, logo, não se trata de uma mera representação cortical do corpo, senão de uma construção multidimensional, na qual aparecem diversos elementos como: o tamanho, a figura, a aparência física, nível de satisfação que a pessoa exerce em seus sentimentos e comportamentos.

Neste sentido, a imagem corporal aparece na necessidade de que cada ser tem de obter uma aprovação social, a qual por sua vez é determinante na satisfação ou insatisfação que depende da importância relativa dada aos julgamentos que aparecem no lócus. 
Para Cash e Szymanski (1995) a satisfação ou insatisfação que cada indivíduo leva em seu cotidiano é definido pelo grau de discrepância existente entre o ideal de beleza que o mesmo toma como referência para sua vida.

É, neste momento, que a imagem corporal ganha sentido na percepção que um indivíduo tem de si mesmo e da experiência emocional ou positiva que o sujeito tem a respeito de como é e como deve ser perante a sociedade, isso implica a uma reflexão de como "me vejo atrativo" e se "minha aparência é relevante, para que eu alcance um determinado êxito social", seja na família, trabalho e/ou entre amigos. Sendo assim a imagem corporal é determinante no grau de funcionamento psicossocial e bem estar das pessoas que atuam como um condicionante na deficiência.

\section{O BELO EM UM CORPO COM DEFICIÊNCIA}

Conforme se vem construindo neste artigo as atitudes sobre a imagem corporal, relacionadas com a forma, funcionalidade e grau de atração que têm as pessoas, principalmente quando se trata destas com deficiência.

Botero Soto e Perez (2014) descrevem várias investigações sobre a influência da deficiência no grau de satisfação das pessoas com a imagem corporal. Sendo que essa satisfação é negativa, uma vez que frente à necessidade de aprovação social, o indivíduo com deficiência se sente excluído, já que não pode alcançar os limites de adaptação no meio social, por problemas de funcionalidade, dor, aparência, entre outras inúmeras possibilidades.

É valido ressaltar que a preocupação com a aparência ultrapassa a deficiência, no sentido que quase todos os indivíduos, independente de algum problema físico ou mental, possuem em maior ou menor grau uma preocupação em se aparentar "normal”, ou seja, "o viés da beleza” opera em quase todas as situações sociais.

Estudos como de Taub, Fanflik e Mclorg (2003) demonstram que as experiências sociais são favoráveis para as pessoas consideradas mais atraentes. Mulheres com deficiência física, por exemplo, são estigmatizadas porque violam as normas de estética corporal, além disso, prevalece o estereótipo de que pessoas, fisicamente atraentes, possuem outras características desejáveis, tais como: inteligência, habilidades sociais, confianças, até mesmo a moral. 
Segundo Lacerda (2007), a morfologia corporal é um fator que influencia no campo da experiência estética, assim sendo, no imaginário social, o estereótipo que se difunde é de um corpo "limpo", "plano", jovem e saudável e em que a estética deixa de ser uma dimensão de superfície e passa a atingir e influenciar as emoções, sentimentos e necessidades das pessoas. Neste cenário as más formações corporais, congênitas ou adquiridas atentam não somente contra a funcionalidade, como principalmente a integridade estética.

Corrobora Sena (2008) que, a aparência é fundamental quando se trata das relações sociais, e chega até mesmo a ser mediadora. A autora considera que a aparência deixa às margens sua superficialidade e se assenta na reconstrução de elementos externos, carregados de uma simbologia e que representam como o indivíduo deve ser e se comportar em uma sociedade contemporânea.

Para Baudrillard (1991), retratar a aparência remete a um modelo desejável da imagem, que atua entre a dissimular e a simular, sendo que no primeiro caso finge-se não ter o que se tem, e no segundo finge-se ter o que não se tem, como em um jogo de parecer e de aparecer. Considera ainda que este modelo leva a mascarar e deformar a realidade, em que fingir ser e possuir não passa de mera simulação, ou seja, uma camuflagem que se apresenta publicamente mais que oculta à essência de cada ser.

Não poderíamos deixar de citar Eco (2004), que coloca a beleza em um campo da relatividade, dependente de distintos momentos da história e da cultura, principalmente no mundo eurocêntrico.

$\mathrm{O}$ autor, que por momentos, coloca a beleza como a equivalência da bondade, percebe-se que no cotidiano essa relação não está somente em como gostaríamos de ser, mas também naquilo que desejamos ser, porém, é preciso saber que conceito de beleza não é algo absoluto e imutável e, portanto, seu significado não pode estar somente atrelado a uma diferença física (Eco, 2004).

No campo da deficiência, é o diferir corporal que parece marcar a construção da imagem no cenário social. Conforme explica Ferrante (2013) existe uma percepção social de que o corpo com deficiência está longe de ser perfeito, esse pensamento condiz às tiranias da perfeição, em que a beleza aparece no corpo idealizado e valorizado por uma sociedade consumista, assim, todos aqueles que por algum motivo, não podem chegar a alcançar um corpo "perfeito" socialmente, que é 
flexível, produtivo, independente e jovem, ficam às margens de um reconhecimento social.

Corroboram Novaes e Vilhena (2003, p.14):

Notamos com isso a atribuição de importância que é dada às diversas partes individuais do corpo. Da mesma maneira, estas passam a assumir características e expressões diversas, dando origem a um corpo liso, fechado e sem asperezas. Qualquer traço involuntário, ou que demonstre sua origem na coletividade, é imediatamente depreciado e rejeitado socialmente.

No entanto, para Kauffman (2003), essa percepção de que a deficiência constrói-se em um corpo totalmente diferente e etiquetado como errado, não somente gera estigma como impede o reconhecimento e a realização de ações para melhorar a qualidade de vida e participação das pessoas com deficiência no cotidiano social. O autor considera que a pessoa com deficiência não necessita de um "manto protetor" e sim de atos que promovam a integração e inclusão social. São as ausências que marcam muito mais a deficiência, que propriamente possuir uma aparência diferente do convencional.

A questão levantada permite considerar que a beleza não pode mais ser olhada a partir de uma ótica de exigência, a qual para ser parte de um meio social o indivíduo deve se adaptar ou camuflar. Considera-se, que pelo menos nos estudos da moda, em que a diversidade é um elemento de criatividade, o padrão estético é observado por meio de distintos campos de análises.

É preciso um conhecimento pragmático de que pessoas com deficiência também se preocupam com a aparência e não querem andar "desvestidos" frente aos demais. O belo é uma condição humana, todos querem que a roupa não seja somente um objeto de proteção e sim uma forma de se expressar socialmente, logo, a compreensão que se atinge é da importância do vestuário em um mundo controlado por aparências, o qual as pessoas usam roupas para alterar seu "parecer" e para "aparecer" frente aos demais com aspectos estéticos mais desejáveis. (Kauffman, 2003; Eco, 2004).

\section{A VESTIMENTA COMO UM MEIO DE INCLUSÃO SOCIAL}

Aborda Sant'Anna (2003, p.68), que "a moda é campo privilegiado da experiência estética" e esta permite que através do vestir a pessoa se aproprie de uma 
infinidade de signos e códigos metalinguísticos que não somente atuam na subjetividade, como nas relações cotidianas.

Contudo, adverte a autora que não se deve confundir a moda em si, com o que é o vestuário. "Este proporciona o exercício da linguagem da moda e atua no campo do imaginário, dos significantes, é a parte integrante da cultura". Para a autora o discurso do vestuário se fundamenta no corpo, visto que é um dos meios de segregar, apontar e até mesmo de corrigir muitos problemas vinculados a anatomia humana (Sant'anna, 2003, p.82).

Para McLuhan (2005), o vestuário aparece como uma extensão da pele, que não somente atua como um meio de proteção, mas como um fator de socializar o indivíduo.

Já Entwistle (2002) considera que os corpos humanos, estão sempre vestidos, uma vez que no cotidiano social é inaceitável que alguém ande sem ter, pelo menos uma roupa que o proteja. O vestuário não somente cobre, mas também enfeita e até mesmo serve para eliminar distorções da aparência, logo é a roupa que distingue e situa uma pessoa dentro de um grupo social.

Dentro de seu conhecimento prévio sobre a imagem corporal, Schilder (1999) também aborda sobre o papel desempenhado pelo vestuário no corpo, em muitos casos passa a ser parte do mesmo, pois quando uma pessoa escolhe um tipo de roupa, está ao mesmo tempo, de forma inconsciente, expondo como quer se posicionar no meio social, assumindo o papel de um indivíduo elegante, desleixado, rebelde, entre outros. Sem dúvida que o vestuário é um meio de modelar a imagem que cada ser carrega de si mesmo.

Observa-se que a roupa é instrumento de inclusão, é possível que o indivíduo ao escolher um tipo de vestuário não está somente utilizando vestimentas convencionais ou querendo se diferenciar dos demais, esta ação carrega todo um sistema de técnicas de adaptação, compensação e até mesmo de desvio da atenção, isso ocorre em todas as esferas sociais e também no campo da deficiência, em que a roupa serve também de um meio para normalização da aparência (Kaiser, Freeman e Wingate, 1985).

Para Liskey-Fitzwater, Moore e Gurel (1993), o vestuário é determinante no contexto da deficiência. Por meio de uma investigação com 35 adolescentes do sexo 
feminino com escoliose e $35 \mathrm{sem}$, as autoras chegaram a resultados indicando que independente da deficiência o vestuário está relacionado à socialização, autoestima e imagem corporal, já que o adolescente procura se vestir de forma semelhante aos demais para alcançar um êxito social.

No entanto, para as adolescentes com escoliose a autopercepção é ressaltada, para este grupo é evidente a importância da estética, em que o vestuário é utilizado para camuflar a condição física, a fim de evitar uma atenção indevida, é por meio da roupa que as adolescentes buscam de alguma forma integrar seus grupos sociais (Liskey-Fitzwater, Moore e Gurel, 1993).

Woltz e Carvalho (2008), pesquisando sobre a importância de um vestuário inclusivo, com base no estudo da ergonomia e com uma aproximação ao público alvo, perceberam que as pessoas com deficiência preferem roupas comuns a roupas funcionais, essa escolha se deve, porque um vestuário comum possibilita uma maior participação social, isso faz com que indivíduos com deficiência usem, em sua maioria, roupas adaptadas de modo que não comprometa a imagem corporal a qual querem demonstrar.

Maffei (2010), em seus estudos sobre o papel do design de moda na deficiência considera que as vestimentas, não são feitas somente para atender as necessidades fisiológicas, visto que carregam uma importante simbologia nas necessidades sociais de autorrealização dos indivíduos.

É valido aclarar que em relação às pessoas com deficiência a roupa designada "adaptada" ou "inclusiva" tem o propósito de levar satisfação a um corpo que possui certas limitações, o que implica não somente em um alcance de comodidade e funcionalidade, mas principalmente, em uma estética que favorece melhor qualidade de vida (Vainshtein, 2012).

De acordo com Azher, Saeed y Kalsoom (2012), ao pesquisarem sobre roupas para mulheres com artrite reumatoide entendem que o conceito de "vestuário adaptado" relaciona-se a uma combinação de características de desenho funcional com estética, onde a pessoa tenha uma maior liberdade de movimento (facilidade para vestir e desvestir), comodidade, bem como que seja agradável esteticamente à medida que favorece a aparência, aumenta a confiança e gera identidade social. 
Para Chang, Hodge e Yurchisin (2014), que investigaram sobre a relação entre os consumidores com deficiência e vestuário, acreditaram que neste cenário prevalecem cinco temas relevantes: a forma, a função, a autoexpressão, a identidade social, a autoeficácia e os signos de aceitação.

Entre vários trabalhos que são referenciados no campo da moda e na sociologia sobre a adaptação do vestuário para pessoas com deficiência, a ênfase não é a criação de peças pensadas para proporcionar maior usabilidade e sim aos diversos fatores que devem levar em conta todos aqueles que fabricam roupas para este grupo social, que são: funcionalidade, estética, acessibilidade, inclusão, entre outros, que demarcam uma relação afetiva entre o produto e o consumidor (Ferreira e Mendes, 2015).

Valério, Medola e Paschoarelli (2015, p.4), em uma ótica do design universal, percebem o grande desafio em se criar uma moda inclusiva que é "criar uma peça do vestuário para ser universal, sem distinção, atendendo a um público grande que vai desde a pessoa com deficiência até pessoas sem nenhuma restrição de movimento". Logo, o vestuário chega à manifestação de agregar, quando é projetado para gerar funcionalidade, proteção e autonomia a todos independente da corporeidade.

Nesta mesma linha de pensamento, De Souza Godinho (2016) analisa o vestuário como parte da aparência, na qual a moda em sua máxima expressão, ao mesmo tempo em que universaliza, possibilita cada indivíduo criar uma personalidade. É no ato de se vestir que o corpo se prepara para se integrar em uma sociedade.

Então, a roupa permite ao indivíduo um equilíbrio entre a necessidade de adquirir uma imagem positiva de si mesmo e ainda possibilita uma autoexpressão frente aos demais. É esse tipo de moda que começa a inquietar-se no meio social, onde também as pessoas com deficiência começam a aderir uma roupa que permita conforto, aceitação, diferenciação e autonomia. O propósito é conseguir uma roupa em que estejam perfeitamente integrados socialmente (Inglessis, 2008). 


\section{CONCLUSÃO}

Este artigo buscou a contextualização no campo acadêmico sobre a importância do vestuário no âmbito das aparências de pessoas com deficiência, as quais necessitam da roupa como um elemento de restauração da independência e dignidade. Neste sentido, a revisão de literatura esteve fundamentada em uma perspectiva teórica interdisciplinar e intertextual, reunindo conceito de Sociologia, Psicologia e Moda.

O que se espera a partir desses dados teóricos é uma reflexão daqueles que fazem "moda", para que levem em conta também as pessoas com deficiências na hora de criarem as tendências. É preciso um entendimento de que também este grupo social requer uma devida atenção em relação a roupas, que não somente oferecem funcionalidade, mas também devem ser confeccionados dentro de uma estética que possibilite um aumento na autoestima, tornando-se meio de inclusão social.

Além disso, os que vendem roupa devem ser propulsores, neste campo, de uma compreensão de indivíduos com deficiência como consumidores demandantes de produtos inclusivos que lhes proporcionem uma imagem positiva no âmbito social. Artigo recebido em Agosto de 2016. Aprovado em Outubro de 2016
DOI:http://dx.doi.org/105965/1982615x10192016085

\section{Referências}

AZHER, N; SAEED, M; KALSOOM, S. Adaptive clothing for females with arthritis impairment. JUMDC, v. 3, n. 2, Jul- Dec, 2012.

BARREIRO, A.M. La construcción social del cuerpo en las sociedad contemporáneas. Papers 73, 2004.

BAUDRILLARD, J. A. Simulacros e simulação. Lisboa: Relógio d'Água, 1991.

BOTERO SOTO, P.A., PÉREZ, C.L. Diseño y Validación de un Cuestionario de Imagen Corporal Para Personas en Situación de Discapacidad Física. Revista Colombiana de Psicología, v. 24, n. 1 enero-junio 2015.

CASH, T. F. Body image: past, present, and future. Body Image, 1, 1-5, 2004.

CASH, T.F.; SZYMANSKI, M.L. The development and validation of the Body-Image Ideals Questionnaire. Journal of Personality Assessment, n.64,p. 466-477, 1995. 
CHANG, H.J.; HODGES, N.;YURCHISIN, J. Consumers with disabilities a qualitative exploration of clothing selection and use among female college students. Clothing and Textiles Research Journal, v. 32, n. 1 34-48, January 2014.

DE SOUZA GODINHO, S. Los mecanismos de la moda en la discapacidad. Revista Inclusiones. v. 3, Número Especial / Enero - Marzo, p. 59-76, 2016.

ECO, H. Historia de la belleza. Barcelona, Random House Mondadori, S.A., 2004.

ENTWISTLE, J. EL cuerpo y la moda. Una visión sociológica. Barcelona: Paidós, 2002.

FERREIRA, T.C.A.; MENDES, F.R.N. Design inclusivo para a moda - percepções sobre a roupa para mulheres com deficiência. $11^{o}$ Colóquio de Moda $-8^{a}$ Edição Internacional $2^{\circ}$ Congresso Brasileiro de Iniciação Científica em Design e Moda, 2015.

FERRANTE, C. Cuerpo, discapacidad y menosprecio social. Ajustes y resistencias a las tiranías de la perfección. En: DEL AGUILA, L.M.et.al (org.). Discapacidad, justicia y Estado: discriminación, estereotipos y toma de conciencia.1a ed. - Buenos Aires: Infojus, 2013.p.99-120.

GOFFMAN, E. A representação do Eu na vida Cotidiana. $14^{\text {a }}$ Ed. Petrópolis: Vozes, 2007.

INGLESSIS, M.G. Communicating through clothing: The meaning of clothing among Hispanic women of different levels of acculturation (Doctoral dissertation). Florida State University. http://diginole.lib.fsu.edu/etd/3871/, 2008.

KAISER, S.B., FREEMAN, C.M., WINGATE, S.B. Stigmata and negotiated outcomes: Management of appearance by persons with physical disabilities. Deviant Behavior, 6, 205-224, 1985.

KAUFFMAN, J.M. Appearances, Stigma, and Prevention. Remedial and Special Education, July/August, v. 24, n. 4, p. 195-198, 2003.

LACERDA, T.O. Uma aproximação estética ao corpo desportivo. Revista Portuguesa de Ciências do Desporto, v.7, n.3, 2007.

LISKEY-FITZWATER,N.; MOORE, C.;GUREL, L.M. Perception of Female Adolescents with and without Scoliosis. Clothing and Textiles Research Journal, n.11, p.17-22, 1993.

MCLUHAN, M. Os meios de comunicação como extensões do homem (understanding media). São Paulo, Cultrix, 2005. 
MAFFEI, S. T. A. O produto de moda para o portador de deficiência física: análise de desconforto. 2010. 90 f. Dissertação (Programa de Pós-Graduação em Design), Faculdade de Arquitetura, Artes e Comunicação da Universidade Estadual Paulista "Júlio de Mesquita Filho". Bauru, SP, 2010.

NOVAES, J.V.; VILHENA, J. De Cinderela a moura torta: sobre a relação mulher, beleza e feiura. Interações, v.8, n.5, p. 9-36, 2003.

OMS - Organização Mundial da Saúde. Classificação Internacional de Funcionalidade, Incapacidade e Saúde - CIF. Lisboa, 2004.

PANTANO, L. La palabra 'discapacidad' como término abarcativo. Observaciones y comentarios sobre su uso. Revista Cuestiones $N^{o}$ 9. Universidad Católica Argentina. Buenos Aires, 2007.

RODRÍGUEZ, H. La conciencia corporal: una visión fenomenológica-cognitiva. Acta Fenomenológica Latinoamericana, 3, 289-308, 2009.

SANT'ANNA, M.R. A moda - o desafio de pensa-lo além do produto. ModaPalavra, Universidade do Estado de Santa Catarina. Centro de Artes. Curso de Moda, v.2, n.2, 2003 .

SCHILDER, Paul. A imagem do corpo: as energias construtivas da psique. $3^{\text {a ed. São }}$ Paulo: Martins Fontes, 1999.

SECCHI, K.; CAMARGO, B.V. Percepção da Imagem Corporal e Representações Sociais do Corpo. Psicologia: Teoria e Pesquisa, Abr-Jun 2009, V. 25 n. 2, pp. 229236.

SENA, T.V. Relações de aparência e construção de novas identidades através do consumo de cópias: bolsas Louis Vuitton na Grande Florianópolis. In: SANT'ANNA, M.R. (Org.). Moda em Santa Catarina: história, crítica e perspectivas. Série Modapalavra. Vol. 5. Florianópolis/Barueri/ SP: UDESC/Estação das Letras, 2008. $272 \mathrm{p}$.

TAUB, D.; FANFLIK, P.L.; MCLORG, P.A. body image among women with physical disabilities: internalization of norms and reactions to nonconformity. Sociological Focus, v. 36, n. 2, p. 159-176, May, 2003.

TAVARES, M.C. F. O Dinamismo da Imagem Corporal. São Paulo: Phorte, 2007.

VALÉRIO, D.; MEDOLA, F.O.; PASCHOARELLI, L.C. Moda inclusiva com foco em mulheres no pós operatório do câncer de mama. 15. ERGODESIGN, Congresso Internacional de Ergonomia e Usabilidade de Interfaces Humano-Tecnologia: Produto, Informações, Ambientes Construidos e Transporte. V.2, n,1, .junho 2015.

VAINSHTEIN, O. Being Fashion-able: controversy around disabled models. En línea]. [Consulta: abril de 2016]. Disponible en: http:// process.arts.ac.uk. 
WOLTZ, S.; CARVALHO, M. A. F.. Vestuário inclusivo: a adaptação do vestuário às pessoas com necessidades especiais. In: COLÓQUIO DE MODA, 4., Novo Hamburgo. Anais, Brasil, 2008. 